\title{
'You're in FunDzaland': Pre-service teachers (re)imagine audience on a creative writing course
}

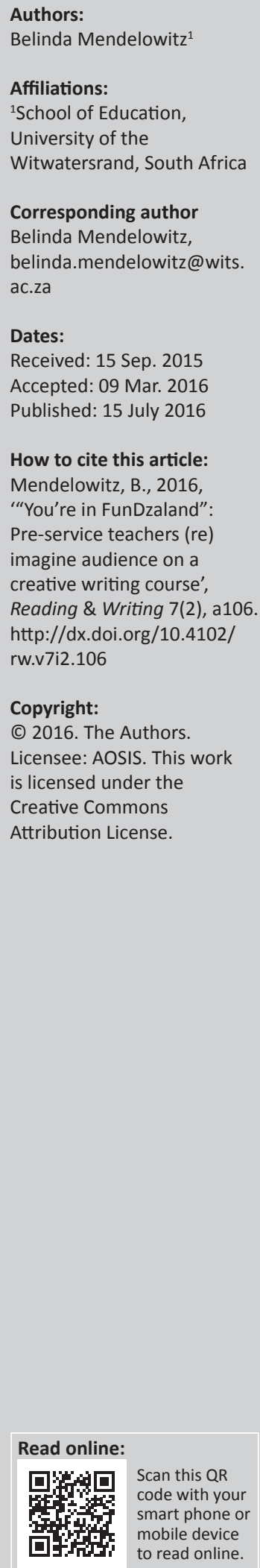

This study explores how collaborative writing for a digital platform can enable students to (re) imagine audience. Although in the context of process writing peer feedback is foreground, in practice, its effectiveness is uneven. The digital revolution offers new opportunities for alternative peer feedback through collaborative writing and re-imagining self and other in the process. This study examines data from a creative writing course in which pre-service teachers wrote collaborative short stories for the FunDza digital site and individual reflective essays about the process. The study's research questions are the following: (1) what were the affordances of this multilayered audience for engaging the students' imaginations? (2) How did this process of (re)imagining audience impact on students' conceptions of themselves as writers? The data set comprised 16 collaboratively authored stories (published on the site) and 34 individual reflective essays. Six of the latter were selected for detailed analysis. Hence, the data for this study encompass detailed analysis of two groups' reflective essays on the process of writing their stories. These groups were selected because they exemplified contrasting collaborative, imaginative writing processes. Group 1 was familiar with the FunDza audience and context, while Group 2 struggled to imagine it. Thematic content analysis was used for analysis. Each essay was read first in relation to the entire data set, then in relation to the other reflections in the author's group. The combination of gearing stories towards the FunDza audience and writing stories collaboratively created two sets of audiences that writers needed to hold in mind simultaneously. Analysis indicates that both audiences challenged students to make imaginative leaps into the minds of an unfamiliar audience, deepening their understanding of the writing process. It also highlights students' mastery of writing discourses and increasing awareness of the choices authors make for specific audiences. Theoretically, this study theorises audience in relation to imagination. A number of concepts have emerged from this research that may enable a more fine-tuned analysis of the audience - imagination nexus. Structured freedom is an important thread that connects the central concepts of audience, imagination and collaboration, foregrounding the idea that imaginative freedom needs to be understood and worked with in nuanced ways. While freedom and imagination are closely related, the provision of free pedagogic spaces with specific constraints in creative writing courses can be extremely productive, as illustrated by the data analysed in this study.

\section{Introduction and overview of argument}

Audience is a central concept in writing and literacy pedagogies, yet it has seldom been conceptualised in relation to imagination. This study focuses on an undergraduate creative short story-writing course for pre-service English teachers, which foregrounds the relationship between audience, collaboration and imagination.

The course has been developed and taught collaboratively and promotes collaborative practice for both lecturers and students. A fundamental principle of the course is that reading and writing are interdependent literacy practices and that writing is a social practice. This means creating opportunities for students to learn to look at a range of texts (their own texts, published texts and texts by other students) in new ways and to extend the notion of audience from writing for the lecturer towards the production of texts for multilayered audiences.

This extended and authentic audience was created by gearing the students' collaborative short chapter stories towards the FunDza site and audience. FunDza's story site is a literacy project that promotes digital reading and writing for a South African youth audience of more than 35000 readers. The FunDza site houses the newly created Wits Teachers' Writing Hotspot, which showcases

Note: Although this is a single-authored article, it reports on a course that was developed, taught and researched collaboratively. Hence, most of the article is written in first person but the section on the curriculum is written in first-person plural to reflect this collaboration. Informed consent was obtained from the six students and their identities have been protected by the use of pseudonyms. 
the best stories from the course, selected by the course lecturers according to an agreed set of criteria (see Appendix 1).

I argue that while gearing the stories towards the FunDza site created an authentic audience for the stories, the constraint of writing the stories collaboratively (in pairs mostly) created an equally important audience for the students' composing process. Both of these audiences required students to make imaginative leaps from their own perspectives into the minds of an unfamiliar audience and peer writing group members. Hence, the writers needed to hold two sets of audiences in mind throughout the process.

In this study, I explore the following questions: What were the affordances of this multilayered audience for engaging the students' imaginations? To what extent was the focus on a specific site and audience enabling for some students and constraining for others? The answers to these questions emerge from an analysis of reflective essays students produced on the course.

\section{Theoretical framework}

Imaginative writing is frequently associated with a complete removal of constraints and absolute freedom to develop ideas as the writer desires (the binary opposite of structure). While freedom and imagination are closely related, this study considers what kind of freedom is most productive for imaginative writing, particularly in relationship to the affordances of different audiences.

Theoretically, this article works with a Vygotskian view of imagination. Vygotsky (2004) argues that imagination is the basis of all creative activity and is central to the production of new ideas and inventions in all areas of cultural life. He views imagination as being closely connected to human intellectual development and higher level thinking as well as emotional development. Thus, Vygotsky presents imagination as a mental function that synthesises cognition and affect. Vygotsky (2004:269) also argues that imagination and freedom are inextricably linked and that one needs to have 'inner freedom of thought, action and cognizing' in order to imagine. However, it is important to note that Vygotsky's notion of imagination extends way beyond the individual (i.e. inner freedom of thought is only a pre-condition for imagining). Rather, imagination entails collaboration between the individual's mind and the social environment (John-Steiner \& Meehan 2000). The richness of a person's imagination will depend on the richness of experiences, cultural resources and tools that they can draw on (Vygotsky 2004).

I take Vygotsky's notion of imagination further and introduce a concept called structured freedom (Mendelowitz 2010) into the field. This concept encapsulates the relationship between freedom, constraints and imagination. Structured freedom facilitates intellectual and affective engagement and imposes structure that opens up possibilities of learners' cognitive and imaginative engagement rather than structure that invites replication (Mendelowitz 2010, 2014). The course discussed in this study explicitly scaffolded the space of structured freedom through a rich range of specific writing and reading activities. In addition, the gearing of the course towards collaborative writing of stories for the FunDza audience created another level of structured freedom. Students had to give careful consideration to their fellow group members and FunDza readers as audiences, thus constraining, directing and opening their creative output.

In the section that follows, I provide a brief overview of the role of audience in writing pedagogy, from the 1980s to the current digital writing age and its reconfiguration of audience. I argue that the focus on audience in process writing pedagogy has met with mixed success and that the advent of digital writing creates powerful possibilities for reimagining audience.

Despite the significant focus on audience in process writing pedagogy, the audience-imagination nexus has received limited attention. One of the major shifts from form focused and product-oriented writing pedagogy was the move to create a 'community of writers' (Zamel 1987) in the writing classroom who are simultaneously writers and the target audience for the writing of their peers. Process writing also repositioned the teacher as a reader and responder to students' writing during the drafting phase and an evaluator of the final product (Calkins 1986; Elbow 1981; Graves 1983; Zamel 1987).

In practice, the effectiveness of peer feedback is uneven and unpredictable. Research has highlighted that peer response is 'a big area of contestation' in writing pedagogy (Wilson 1994:29). In his research with teachers on a process pedagogy writing programme, Wilson found that one of the biggest obstacles to the implementation of process writing was the difficulties teachers experience with peer response. One of the main reasons cited for this difficulty was that teachers frequently did not train learners to give and receive feedback productively. But even when training is provided, there is no guarantee of success. Some peer feedback groups work better than others, often depending on the level of commitment, the relationships between group members and the extent to which group members have mastered the discourse to talk productively about a piece of writing (Mendelowitz 2010).

Andrews and Smith (2011) argue that school writing still has:

too limited a sense of audience and function, so that writing becomes an activity that serves assessment requirements in school and the educational system, rather than a form of communication that can make a difference in the world. (p. 9)

Andrews and Smith (2011) conclude that writing for a real audience is critical to generate student engagement in writing tasks and for higher quality writing products.

The imagination-audience nexus (the mechanisms and processes through which young writers imagine and invent stories and audience) is beginning to receive some attention. Mendelowitz $(2010,2014)$ argues that imagining audience can 
entail four imaginative moves: imagining the story for oneself and for an unfamiliar audience, using linguistic resources to create the story and enabling an outsider to imagine the scene. Learners are encouraged to make something to: present, through opening their imaginative capacities and the use of evocative language. The process entails minimising distance and enabling the readers to project themselves into the story. This account of the imaginative-audience nexus can be applied to print-based or digital writing contexts.

The digital revolution has significantly altered our understanding of audience and the nature of audience. The carefully delineated writing process, as discussed above, is no longer applicable in digital spaces. Process and product frequently merge as composition and publication become one integrated entity. Writers can post drafts as well as final products on the web, and feedback can be immediate from known or unknown readers (Andrews \& Smith 2011). While audiences and writers in a pre-digital age were separated by time and space (with audiences mostly being relegated the role of passive recipient and interpreter), in new digital media the time and space between writer and audience has collapsed. The audience has a much more active role, which ranges from comments posted on Facebook to Fan pages or collaborative writing using synchronous technology. While the extent of audience participation in digital writing varies, what is not in question is the broader, multiple, local and global potential reach of audience in digital spaces. Both Andrews and Smith (2011) and Deumart (2014) discuss the collaborative and creative potential of writing in digital spaces in relation to audience.

Hull and Stornaiuolo (2010) make some productive links between audience in digital media and imagination. They extend the concept of 'transliteracies' (the ability to read, write and interact across a range of platforms, tools and media) to include the capacity to imagine self and other in the digital authoring process (Thomas et al. 2007). This includes 'the "critical and hospitable" dispositions necessary for self and other work - the eloquent negotiation and co-existence with unknown but imagined others' (Hull \& Stornaiuolo 2010 cited in Andrews \& Smith 2011:127).

So far, I have framed the relationship between imagination, audience and collaboration in a digital age, with structured freedom as the thread that links these three key concepts. In the sections that follow, I explore the applications of these ideas to the creative writing course that is the focus of this study.

\section{The curriculum}

The course aimed to create a space for English III students to become writers through engaging with reading and writing processes intensively. While there have been various configurations of the course, the focus of this study is on the current version in which students produce stories collaboratively for the Wits Teachers' Writing Hotspot on the FunDza platform. Students were required to engage with the specific audience, format, content and language of the FunDza stories and its implication for the development of their own stories. Stories for the FunDza site are usually written individually. However, we decided to set up a collaborative writing assignment as the chapter structure of FunDza stories seemed ideally suited for extending the collaborative writing focus of our course (see Appendix 2: assignment brief)

FunDza publishes a chapter a day of stories written by young people, with themes, styles and discourses aimed at a youth audience, through a mobi and online publishing forum. These stories have a massive readership and are set up in a dialogic way such that readers can respond to and comment on each day's chapter. The mobi forum is particularly cheap and accessible on reader's smart phones. The chapter-a-day format has led to a certain kind of literary shape: namely, the kind of plot, scene and character which will motivate the reader to come back tomorrow for the next instalment. Plots involving strategic placing of climax and motive, cliffhanger chapter endings and other devices to maintain reader interest have become the hallmark of many youth stories in the FunDza catalogue (Mendelowitz \& Lazar 2015).

Students were required to read a variety of different literary story types, including canonical stories, contemporary literary stories and several FunDza stories. Several classes were allocated to teaching and analysing these stories with the aim of providing both models and anti-models for students' own writing. The term 'anti-models' refers to stories that students did not want to emulate. We use the term models and anti-models as springboards for the students' own writing, not as templates for replication. As students' own stories evolved, they were invited to identify which elements of the read stories they found interesting, worthwhile and influential and which they did not. In this manner, students became more reflexive and critical readers and writers.

The constraints of writing collaboratively for the FunDza site challenged the students to reimagine audience at a number of levels. The Students started off the course as readers of the FunDza stories. However, they soon became the audience for their own writing and writing produced by their peers, starting with short writing tasks. Students were then required to write a four-chapter story for the FunDza audience in pairs. Once they formed their groups and began brainstorming and writing their stories, the collaboration included a carefully structured editing process. The lecturers and trained writing consultants were facilitators at every stage of the process. The collaborative pairs were then widened to include more varied and fuller class feedback. Finally, the actual FunDza audience and its interests were the projected audience of all the stories. Every decision in the writing process was ultimately influenced by the FunDza audience and the group collaborative processes (Mendelowitz \& Lazar 2015).

\section{Methodology}

Each group wrote a story collaboratively and wrote individual reflective essays (see Appendix 2). The broad data set is 
comprised of 16 stories that were published on the Wits Teachers' Writing Hotspot, and the individual reflections (34 reflections). From these 34 reflections, I selected 6 reflective essays for detailed analysis. Hence, the data for this study comprise a detailed analysis of two groups' reflective essays on the process of writing the story collaboratively.

Most groups consisted of pairs. However, the two groups selected for analysis consisted of groups of three. Hence, six reflections from two groups are analysed in detail from the broader data. The two groups (six reflections) were selected because they exemplified varied collaborative, imaginative writing processes. Group 1 was familiar with the FunDza audience and context, while Group 2 struggled to imagine it.

I use thematic content analysis to analyse the reflective essays. Each reflective essay was read first in relation to the entire data set, then in relation to the other reflections in the relevant writing group. As imagination, collaboration and audience are the focus of this study, it was important to select and analyse the sample reflections per group and to see how the reflections provided insight into the individual and group process and how they articulated with each other. I analysed the data in relation to two key categories. These two categories are both concerned with imagining audience and facilitated an analysis of the role of audience in the reflections from a number of different perspectives as follows:

Category $\mathbf{1}$ - Imagining audience by reading published texts (reading-writing relationship)

Category 2 - Collaboration and audience: the constraints and affordances of peer and FunDza audience

It is important to bear in mind that reflective essays as a form of data have specific affordances and limitations. One cannot ignore the fact that the essays were evaluated by the course lecturers for a mark, and while many were fairly candid, it is possible that some students pandered to their perceptions of lecturers' expectations. However, on the whole there is enough richness and range to consider the data valuable and insightful.

\section{Data analysis}

Group 1 consists of two black females (Kedi and Dimpho) and one black male (Thabo). The three group members are close friends and worked well together. Group 2 consists of three white females who are also close friends (Mary, Eve and Rolene). Although Group 2 ultimately produced a coherent and effective story, they struggled with aspects of the collaborative process.

Both stories were engaging and gripping but entirely different in terms of genre, style characterisation and context. Group 1 's story is a human drama about an orphan who is bullied at school. The story engages the reader at a powerful emotional level and is clearly located in an African setting, though not specifically South Africa. In contrast, Group 2's story is a crime thriller which engages the reader by creating mystery and intrigue. However, Group 2's story does not have a strong South African setting. In terms of popularity with readers, there is not a significant difference between the two stories: Group 1's story got 12 likes, while Group 2's story got 8 likes. By comparison, the most popular stories on the Hotspot site received 49 and 55 likes.

Group 1 received a total of 19 comments on their story, while Group 2 received 17. The responses of the FunDza readers to their stories seem to be predominantly shaped by the genre. Responses to Group 1's story tend to be more emotionally and personally engaged, with particularly strong, extended responses to chapter 1. Responses to Group 2's story were mostly predictions about the plot (whodunit?). However, as a response to a genre that builds towards a denouement, there were five quite elaborate responses at the end of chapter 6 , commenting on the ending and quality of the story.

In the section that follows, I present a detailed analysis of reflective essays from Group 1 and 2 per analytic category. I begin with category 1.

\section{Category 1: Imagining audience by reading published texts (reading-writing relationship)}

The study and analysis of published short stories (both print based and FunDza stories) played an important role in group 1 's evolving understanding of audience and craft. While some groups regarded the FunDza stories as anti-models, this group identify strongly with the context, characters and themes of the FunDza stories as it resonates with their own lives (i.e. they are part of the target audience). However, this easy identification was not without its limitations.

Kedi comments on this:

'What really amazed me is the manner in which all these stories have characters that we can closely relate to. The stories depicted societal issues that did not force one to delve into one's imagination to create a picture of what is happening in the story'.

Kedi is suggesting that the stories are so close to her real-life experience that limited imaginative effort is required to visualise the story. While tapping the familiar provides an easier access point into the stories, it creates a challenge of rendering the familiar in fresh and unclichéd, defamiliarised ways (Mendelowitz \& Lazar 2015).

Kedi explores this challenge further in her reflection as follows:

'We found ourselves trying to create characters and plots that resembled those from the FunDza stories and after visiting the site to see more of the stories, we began to copy small saying and actions without noticing. This was negative because our characters became voiceless and I personally felt that I was using them because of the fear of becoming irrelevant for the audience'.

Kedi's comment highlights the limitations of writing for a specific audience with exposure to many models of the target stories, and as part of the target audience themselves. They 
struggled to create a story with a fresh approach and found themselves in reproduction rather than creative reworking mode (Vygotsky 2004). Their solution to this problem was their decision to base the story in another African country 'yet keep the experiences real and non-fiction'. It is interesting that Kedi refers to the genre of the FunDza stories as 'nonfiction', another indicator of the challenges of fictionalising the familiar and the everyday.

However, despite these challenges, Kedi shows that she has gained valuable insights about writing and audience from reading the FunDza stories. Kedi discusses specific stories in detail and reflects on their impact on her as a reader, then applies these ideas and crafting devices to her own writing process. She concludes that:

'Not Him is the epitome of what suspense in a story should be. Each chapter leaves one yearning for more. Reading such stories plays a significant role on one's own writing'.

Kedi was particularly inspired and excited by the realisation that 'it is possible to create an antagonist who is introduced as a protagonist earlier in the story'. This device made her realise that there are a number of different ways to engage readers and that these devices can be used simultaneously:

'This actually helped me realise that a story comes to life when you create events that the reader will relate to and also ones that will leave the reader in a shocked state, yet wishing there was more to read'.

On the same theme of playing with the reader's expectations, she also learned from another FunDza story (For Love or Money) about doing a creative reworking of an existing story, using a modernised fairy-tale frame. Dimpho and Thabo do not provide as much detail about the reading-writing interface as Kedi does. Thabo, in particular, is more focused on collaboration and the affective element of the writing journey. Both Dimpho and Thabo make special mention of The Playa as a story that had a positive impact on them. Dimpho comments that she particularly liked this story as it 'gives the reader a VIP pass into the head of all the concerned characters'. She is referring to the shifting narrative point of view of the story. Thabo comments that he learned different techniques of telling a story 'without being predictable but yet keeping the reader glued to what they are reading'. What he particularly appreciated about 'The Playa' is the author's use of everyday language which facilitated 'a real connection to the text; he captured reality and put it so well in words'.

It is worth noting that none of the Group 1 members made mention of any of the more traditional print-based stories, preferring the FunDza stories. This was not the case with a significant number of students who were critical of the FunDza stories. Group 2, for example, viewed the FunDza stories mostly as anti-models. While the reasons provided for this were all literary, it is possible that they also felt positioned as outsiders by the FunDza stories.

Mary is an avid reader and her preference is for canonical texts. Hence, it is not surprising that her favourite text was
The Story of an Hour by Kate Chopin. Like Kedi, She describes her response to this text as a reader and how she then applied some of the crafting devices to her writing:

'Throughout the text the reader is taken on a rollercoaster of emotion .... As the reader I loved this and tried to channel this form of story-telling while being descriptive on abstract things such as emotion but still keeping the mystery in the story'.

While Mary does not specifically mention any of the published FunDza stories as positive or negative influences, she was inspired by the work of one of the tutors (Fran), who is a FunDza writer and shared a sample of her draft story with the whole English III group. After hearing Fran read her work and talk about her writing process, she was 'filled with ideas'. She was particularly inspired by the quality of Fran's writing rather than the theme of Fran's story. She concludes that 'it was with this quality in mind that I tried to write my own chapter for this short story'. This comment highlights the potential of creating opportunities for students to engage with writers directly and to gain insights into the messy and creative process usually hidden from view when one reads published works.

In contrast, Eve had a negative response to most of the stories studied on the course, and said that they 'did not necessarily help me with my writing. I found some catching stories but also found boring and flat ones'. The only story that Eve really enjoyed was 'The Playa'. Like Dimpho and Thabo (from Group 1), this story gave her insight into 'what the character was thinking. This made me feel as if I was in the character's head'.

However, on the whole, she regarded the texts included in the course as anti-models. She realised that for a story to be successful, the story 'needs to grab you and make you feel as if you are in the book itself' and she felt this was lacking in the majority of stories provided. She concludes:

'The texts that I have read on this course have influenced me positively. This is because I wanted my story to differ'.

Rolene makes a similar point in her reflection about the FunDza stories serving as anti-models. After reading the two FunDza stories in the course pack, she concluded that:

This was not how I wanted our story to be, and my group agreed with me. I found these stories to be clichéd, excessive and overly sentimental. I also found these two stories to be very predictable, with no suspense to keep the reader interested. Therefore, we chose to prioritise the detective genre to create suspense and to allow the romantic plot to be hinted at.

Although the two groups engaged differently with the stories, what is common to both sets of data is the focus on audience and the ways in which students moved fluidly between thinking about their own responses as readers, the crafting devices that facilitated these responses and its implications for themselves as writers. While students have had many experiences of analysing texts at school and in other university courses, the shift here is that they are looking at texts through a writerly lens. The second striking commonality is the 
students' mastery of writing discourses and their increasing awareness of the choices one needs to make as a writer in relation to the impact one wants to have on an audience. These shared writing discourses also play an important role in the students' reflections on collaboration and audience, the second analytic category.

\section{Category 2: Collaboration and audience: the constraints and affordances of peer and FunDza audience}

Group 1 and Group 2 faced different challenges with the collaborative writing process. Group 1 members felt challenged to meet their expectations of their fellow group members, while Group 2 members experienced power struggles and conflict about some key elements of the decision-making process. These two contrasting collaborations highlight the constraints and affordances of collaborative writing for the FunDza audience. They also illustrate the Vygotskian idea of imagination as a synthesis of mind, social environment, experiences and cultural resources in different ways. Group 1 mobilises the collaborative imagination productively, while Group 2 members at time view the collaborative imagination as a hindrance to individual idea development and story ownership.

Dimpho describes how her hunger for a real audience was awakened after a talk presented to her class by Dorothy Dyer and Roz Haden from the FunDza Literacy Trust. She comments: 'By the time they left all I wanted was to write and have someone read my word and the response would not be in red pen'. However, she experiences a new level of performance pressure posed by her group members at the first layer of audience:

'Thabo had been teaching for 8 years before he came to Wits. Kedi is just a great writer herself. This pushed me to a level I had never seen myself on. There is a lot of expectation on them and their work. ... I started writing in a way I'd never written before. That is a growth, one I am proud of. One I wouldn't have experienced if I hadn't taken up this challenge and worked with them as a group'.

In a similar vein, Thabo was initially anxious about collaboration and was concerned that he did not have much to offer the other two members of the group:

'The fact that it was a group task really killed me.... My thoughts were weighing me down as I wondered what I had to offer these girls who have it all together'.

Thabo alternates between self-doubt and overwhelming excitement. He was excited by the first meeting when the group developed their storyline. However, the excitement is soon replaced by anxiety about the 'insurmountable mountain' that awaits them; the realisation that 'an awesome story line' is really just the beginning of a worthwhile but difficult journey. It is interesting that he does not initially recognise his teaching experience as a resource, yet this is recognised by Dimpho.

Like Mary from Group 2, Thabo experienced the talk by Fran about her draft FunDza story as a turning point:
'It was if a wave hit me, then I learned that I actually needed to believe in myself again. Just like Humpty Dumpty, I was picked up from the ground and put together again'.

After this turning point, Thabo begins to view the collaborative space as a safe space 'where I could be allowed to be me and a space where I could make mistakes without being laughed at'. The realisation that even an experienced writer like Fran struggles at times seemed to give Thabo the permission to view the collaborative space as one that is rich in resources and learning possibilities, rather than a threatening space.

Of the three group members, Kedi is the most confident writer. Her initial resistance to collaborative writing was the concern that 'my ideas are too good to be crushed'. However, she began to appreciate the opportunities 'to think and see things through a new lens'. Rather than focusing on the loss of her individual ownership of ideas, she concludes that the collaborative process was extremely generative, offering a wider spectrum of thought and thus removing the pressure of needing to generate an entire story individually. She concludes:

'I have grown as a writer, courtesy of this course. This has assisted me in accepting the ideas of others people, their criticism and mostly their ability to redirect my thoughts and also decide about what actually goes into the writing piece and what does not'.

What is striking about Group 1's collaborative process is the deep level of investment in the process. The stakes have clearly been raised to a new level in terms of peers as audience. Students know that they will be allocated a group mark for the story and that one of the criteria is about story coherence and group process. They also do not want to let their partners down. Here we see structured freedom in action, the freedom created by boundaries and structures that facilitate imaginative, affective and cognitive engagement. The constraints of having to negotiate with peers towards a final product forces a certain level of focus, discipline and carefully considered choices about craft, plot, characters and audiences.

The other significant element is obviously keeping the FunDza audience in mind at all times, and this too had difficult and constraining elements. This group constantly reviewed and revised their plot, content and language in relation to its imagined reception by the FunDza readers. Kedi commented:

'When drafting the story for the first time, we questioned how the FunDza audience will receive it, if the language will be understood and also if they can relate to it on some level. This made the writing more difficult because with every second scene or dialogue that occurred, I scrutinized and tried to correct things, even though there were no mistakes. The entire process has made one more cautious about what happens on the receiving end of the story'.

Thabo adds another insight to this discussion about the imagined audience. Although previously I have said that 
Group 1 are members of the target audience, they are on the older side of the age continuum. Hence, they still need to do some imagining of a younger target audience. Thabo describes this process as follows:

'My writing processes were pretty much shaped by the FunDza stories for simple reading. Teenagers spend too much of their time on their phones and the fact that such writing reaches them like instant messages made me realise that in order to appeal to this group, one would have to be interesting in their way of telling a story so as not to lose them'.

If I was writing this article 10 years ago or more, I would have concluded that these reflections indicate a shift from writerbased to reader-based writing (Flower 1989:188). While this concept is still applicable to some extent, it cannot account for the radical shift in audience on digital platforms, particularly the more active role of audiences as responders. Hence, Thabo is referring to this specific audience of FunDza readers who will make negative and positive comments about each chapter in real time.

On the whole, Group 2 focused more on the challenges of writing for each other as audience than on the FunDza audience. This may be as a result of some conflict and power struggles within the group as well as their resistance to the FunDza stories and audience.

Mary finds it easier to write individually, using her own style and voice. Hence, it was a challenge to incorporate two other styles and voices into the story. She discusses the delicate balance needed between achieving a high-quality story and being sensitive to the other group members. However, she concludes on a positive note:

'I was pleased with the end result as Ibelieve we all communicated well with one another and really took each other's opinions into account'.

Mary also refers to the wider community of writers and audiences in the class, including lecturer feedback and exposure to stories by other groups in the class. Feedback from the two lecturers seemed geared to help the group to focus more strongly on the FunDza format and context. This is not surprising given their ambivalence about the FunDza stories as described in category 1. Mary describes this feedback as follows:

'After reading our first two chapters, Dr N gave us the good piece of advice that the last paragraph of our chapter should be more gripping and entice the reader to continue reading. Dr B suggested we root the story more deeply in South African culture. I believe this was valuable advice because these little details are what make the story more believable'.

Eve also found collaborative writing tougher than individual writing. She shared Dimpho and Thabo's initial anxieties about meeting the expectations of group members. She comments:

'Although you have each done your own work and put effort in, it might not always be good enough for the others in your group and putting [the story/ideas] together is difficult'.
However, she concludes that despite their differences 'we seemed to eventually put it together and get it done'.

Rolene describes her reaction when she first heard about the assignment, at the beginning of the course:

'I was petrified because I felt that I was incapable of turning my thoughts and ideas into a story. I decided to take this assignment as an opportunity to develop and improve my creative writing skill'.

Rolene wrote the first two chapters and enjoyed the task of delineating and developing the different characters. However, Rolene found the collaborative process extremely difficult. Challenges included 'ideas that clashed' and six chapters that did not flow coherently. Having introduced the characters in the first two chapters, she felt a strong sense of ownership for these characters and grew increasingly irritated as 'my group members did not seem to understand the characters that we had created and so they kept changing the characters' personalities'.

Maintaining coherence between chapters was a challenge. This was particularly the case for two specific chapters, which Rolene argues are significantly different to the rest of the story. This seemed to be the result of a power struggle, in which one of the writers resisted the input and opinion of the other group members. Rolene concludes:

'Despite this, I thoroughly enjoyed working with my group members because we were able to generate excellent ideas for the story which I do not think I would have managed to do on my own'.

Regarding the FunDza audience, Group 2 was, according to Mary, careful 'to keep the story within respectable bounds' suitable for young people. In particular, they wanted to write a story that was 'positive and uplifting' and to avoid the heavy social issues such as rape and teenage pregnancy. This was a concern raised by a significant number of students in the broader data set.

Mary comments:

'I believe that because we had an older high school audience in mind the story reflects the thoughts, feelings and language that a high-schooler might have and feel'.

Eve found writing for the FunDza site 'an exciting journey not only because you need to think about the audience but because it helped me through my writing process step by step. It helped me to decide what age group to look at and what this age group was after in a book'. In other words, Eve found the constraints of a specific audience and format productive.

Interestingly, both Mary and Eve focus on the audience in quite a generic way, as children of a particular age with little explicit attention to the other defining features of the FunDza audience. Rolene focuses on the more practical aspects of writing for the FunDza site - topic selection and format. 
While she enjoyed the freedom to choose a specific topic for the story, she found the chapter format restrictive, limiting the flow of their story. All three group members struggled to make the imaginative leap into the minds and experiences of an unfamiliar audience, hence needing to confront the limits of their collective imagination. From a Vygotskian perspective, it could be argued that they lacked the cultural resources needed for the imaginative leap and were reluctant to mobilise these resources through alternative channels such as research or cultural informants.

Mary makes an insightful comment about the purpose of writing for a range of audience which reflects a deepening understanding of the audience-imagination nexus:

'Writing is about opening ourselves up to communication across boundaries whether they be cultural or social boundaries or the boundary of time and physical space'.

I found this comment particularly interesting because this group seemed to struggle to imagine the FunDza audience and were ambivalent about the FunDza stories. They were determined to write the FunDza stories on their own terms, while keeping the audience in mind - a delicate balancing act which was ultimately successful (given that their story was selected to be published on the site and received a positive response from readers).

A striking feature of Group 2's collaborative process is the challenges of making creative choices when there is a bigger repertoire of ideas, styles and voices available. There were clearly power struggles around these decision-making processes, with group members showing different levels of receptiveness to group feedback. This conflict points to an important aspect of collaboration - there are inevitably ideas that get lost along the way. However, I argue that such conflict is an important part of the learning process. The three group members ultimately embrace the view that this was a positive learning experience resulting in 'a more creative outlook and growth' (Mary), 'an exciting journey' (Eve) that generated better ideas collectively 'than I could have managed to do on my own' (Rolene). Their process illustrates another element of structured freedom - some individual creative freedom was lost but as a result of these constraints there were definite cognitive and imaginative gains.

Although the two groups have different relationships to the imagined FunDza audience, there are some interesting commonalities. Both groups seem to view this audience through their teacher lenses. While Thabo comments that they 'spend too much time on their phones', Rolene constructs the audience as needing protection from certain 'heavy topics'. Hence, their constructions of teenagers also shape the ways they develop their stories.

\section{Conclusion}

At the outset of this article, I problematised the limited writing pedagogy scholarship focused on the relationship between audience and imagination. I also argued that the focus on audience in process writing pedagogy has met with mixed success. This study has attempted to bridge this scholarship gap both theoretically and empirically.

Empirically, the most significant finding to emerge from this research thus far has been the productive constraints of collaborative writing for a digital platform as a result of the provision of multiple audiences, some digital and some in the classroom. Clearly, there are no formulae for creating engaged audience-writer relationships in creative writing courses. A digital audience on its own will not guarantee more engagement, neither will collaborative writing. However, it does emerge strongly from the data that the combination of writing collaboratively for a digital audience created productive and focused writing/imagination/audience relationships. Writing in collaborative groups generated a sense of accountability and investment that is sometimes absent in artificially created peer feedback processes on individual writing tasks. It also gave students access to a more diverse range of ideas, resources and tools for their stories, going beyond individual imaginings towards a shared story imagination. This illustrates the Vygotskian notion of imagination as a collaboration between the individual and socio-cultural environments (John-Steiner \& Meehan 2000). While Group 1 members viewed this collective imagination as highly productive, Group 2 members were more ambivalent about the losses of individual ideas and ownership during the writing process. However, they ultimately conceded that the collaborative journey enabled them to grow in new ways as writers.

In addition, the focus on writing for a specific audience and platform bought the notion of audience into a sharp and finetuned focus. The specific FunDza format of chapters with cliffhangers pushed students to consider regularly how to keep the audience engaged. While these two constraints (collaborative writing and the digital platform) at times created diluted stories, discomfort, anxiety, tensions and power struggles, I conclude that these constraints were ultimately productive and facilitated deep levels of imaginative and cognitive engagement. It should be noted that this imaginative-cognitive synthesis is evident in the student reflections, which contain carefully formulated ideas and creative play with language at times.

Theoretically, a number of concepts have emerged from this research that may enable a more fine-tuned analysis of the audience/collaboration/imagination nexus. Structured freedom is an important thread that connects the central concepts of audience, imagination and collaboration, foregrounding the idea that imaginative freedom needs to be understood and worked with in nuanced ways. While freedom and imagination are closely related, the provision of imaginative pedagogic spaces with specific constraints in creative writing courses can be extremely productive.

The possibilities of making writing 'more real, for real audiences, and in preparation for the real world' (Andrews \& Smith 2011:38) are multiple. As I am writing this conclusion, 
the \#Fees Must Fall student movement is spreading like wild fire. South African students are finding new audiences for their protest locally and globally, mostly though social media. Traditional hierarchies have been subverted as Vice Chancellors meet with students on their terms, literally sitting on the floor alongside students. The possibilities of writing for digital audiences are endless, and this most recent social movement illustrates this point in powerful ways. While the focus of this study has not been on political protest writing, the recent events are a reminder that there are powerful possibilities for enabling students and educators to rethink audience in even deeper, more immediate ways and its implication for classroom practice.

\section{Acknowledgements}

Thanks to Karen Lazar, Navan Govender and Michelle Friedman for a productive collaboration. Thanks to Karen Lazar, Toni Gennrich, Laura Dison and the two reviewers for valuable comments on earlier versions.

\section{Competing interests}

The author declares that she has no financial or personal relationships which may have inappropriately influenced her in writing this article.

\section{References}

Andrews, R. \& Smith, A., 2011, Developing writers: Teaching and learning in the digital age, McGraw-Hill/Open University Press, Berkshire.

Calkins, L., 1986, The art of teaching writing, Heinemann, Portsmouth.

Deumart, A., 2014, Sociolinguistics and mobile communication, Edinburgh University Press, Edinburgh.

Elbow, P., 1981, Writing with power, Oxford University Press, Oxford.

Flower, L., 1989, Problem solving strategies for writing, 3rd edn., Harcourt Brace Javanovich, New York.

Graves, D., 1983, Writing: Teachers and children at work, Heinemann, Portsmouth.

Hull, G.A. \& Stornaiuolo, A., 2010, 'Literate arts in a global world: Reframing social networking as cosmopolitan practice', Journal of Adolescent \& Adult Literacy 54(2), 85-97. http://dx.doi.org/10.1598/JAAL.54.2.1

John-Steiner, V.P. \& Meehan, T.M., 2000, 'Creativity and collaboration in knowledge construction', in C. Lee \& P. Smagorinsky (eds.), Vygotskian perspectives on literacy Research, pp. 31-48, Cambridge University Press, Cambridge.

Mendelowitz, B., 2010, 'The elusiveness of imagination: A case study of five teachers' conceptions and enactments of imaginative writing pedagogy in Gauteng classrooms', Unpublished doctoral thesis.

Mendelowitz, B., 2014, 'Creating classroom environments of imaginative (im) possibilities', English in Education 48(2), 164. http://dx.doi.org/10.1111/eie.12041

Mendelowitz, B. \& Lazar, K., 2015, “Even if it's my story it can have your touch": Developing a culturally responsive writing pedagogy', Paper Presented at WILLS conference, Wits University, Johannesburg, August 2015.

Thomas, S., Joseph, C., Lacceti, J., Mason, B., Mills, S., Perril, S. et al. 2007, 'Transliteracy: Crossing divides', First Monday 12(12).

Vygotsky, L.S., 2004, 'Imagination and creativity in childhood', Journal of Russian and East European Psychology 42(1), 7-97 (originally published in Russian in 1930).

Wilson, D., 1994, Attempting change: Teachers moving from Writing projects to Classroom Writing, Boynton/Cook, Portsmouth.

Zamel, V., 1987, 'Writing: The process of discovering meaning', in M.H. Long \& J.C. Richards (eds.), Methodology in TESOL: A book of Readings, pp. Heinle \& Heinle, Boston. 


\section{APPENDIX 1: Assignment rubric}

Assessment rubric A: Creative Story ENG3080 2015 NAMES \& STUDENT NUMBERS:

\begin{tabular}{|c|c|c|c|c|c|}
\hline LITERARY COMPONENTS: & $\begin{array}{l}\text { Level } 1 \\
\text { below } 50 \%\end{array}$ & $\begin{array}{l}\text { Level } 2 \\
50-59 \%\end{array}$ & $\begin{array}{l}\text { Level } 3 \\
60-69 \%\end{array}$ & $\begin{array}{l}\text { Level } 4 \\
70-74 \%\end{array}$ & $\begin{array}{c}\text { Level } 5 \\
75 \% \text { and above }\end{array}$ \\
\hline $\begin{array}{l}\text { STYLE: } \\
\text { Syntax, grammar, spelling, } \\
\text { punctuation } \\
\text { Literary style: } \\
\text { Originality, polish clarity; } \\
\text { showing not telling; } \\
\text { avoidance of cliché and } \\
\text { hyperbole, audience- } \\
\text { appropriate language, } \\
\text { vividness of expression }\end{array}$ & $\begin{array}{l}\text { Language impedes meaning } \\
\text { and sense. } \\
\text { Poorly constructed } \\
\text { sentences, faulty spelling, } \\
\text { punctuation and } \\
\text { apostrophes, muddled use } \\
\text { of tense. Style dull or } \\
\text { uninteresting, not suitable } \\
\text { for audiences or setting. } \\
\text { Tells more than shows. Two } \\
\text { partners' styles not } \\
\text { compatible. }\end{array}$ & $\begin{array}{l}\text { Language unclear. } \\
\text { Frequently faulty sentence } \\
\text { structure, spelling, } \\
\text { punctuation and } \\
\text { apostrophes, muddled use } \\
\text { of tense. Unpolished with } \\
\text { poor editing. Style lacks } \\
\text { colour and interest; } \\
\text { tendency to cliché and } \\
\text { exaggeration. Style doesn't } \\
\text { fit topic/audience. Tells } \\
\text { more than shows. Partners' } \\
\text { styles incompatible. }\end{array}$ & $\begin{array}{l}\text { Mainly good sentence } \\
\text { structure. } \\
\text { Spelling, punctuation and } \\
\text { apostrophes, and tense } \\
\text { only occasionally faulty. } \\
\text { Language quite clear, vivid } \\
\text { literary style emerging. } \\
\text { Fresh use of imagery and } \\
\text { observation. Dialogue and } \\
\text { character well-expressed. } \\
\text { Suitable for audience }\end{array}$ & $\begin{array}{l}\text { Clear language, well-polished. } \\
\text { Correct sentence structure. } \\
\text { Confident and accurate use } \\
\text { of spelling, punctuation, etc. } \\
\text { Style is lively and vivid and } \\
\text { appropriate to audience, } \\
\text { topic and character. Little or } \\
\text { no cliché, language fresh } \\
\text { and vibrant, good use of } \\
\text { imagery and sensory } \\
\text { observation. Shows more } \\
\text { than tells. Partners match. }\end{array}$ & $\begin{array}{l}\text { Excellent, very few errors. } \\
\text { Shows clear signs of } \\
\text { having checked own and } \\
\text { partner's language. } \\
\text { Polished and accurate. Uses } \\
\text { lively and original imagery } \\
\text { and vocabulary. Suitable } \\
\text { and interesting style and } \\
\text { dialogue. Shows more than } \\
\text { tells; partners' styles } \\
\text { compatible. }\end{array}$ \\
\hline $\begin{array}{l}\text { CONTENT: } \\
\text { Approach to task and topic; } \\
\text { overall effectiveness of } \\
\text { story, originality and } \\
\text { impact, readability and } \\
\text { level of interest, point of } \\
\text { view and character; setting } \\
\text { and atmosphere; dialogue } \\
\text { and language choice }\end{array}$ & $\begin{array}{l}\text { Demonstrates little or no } \\
\text { understanding of task. } \\
\text { Confused, text jumps from } \\
\text { point to point, lacks clear } \\
\text { direction or development } \\
\text { of story, lacks consistency } \\
\text { of approach to topic, } \\
\text { character, and setting. } \\
\text { Unoriginal, tendency to } \\
\text { cliché, exaggeration, dull } \\
\text { dialogue. Excessive direct } \\
\text { or literal telling }\end{array}$ & $\begin{array}{l}\text { Demonstrates limited } \\
\text { understanding of the task } \\
\text { or the requirements of } \\
\text { creative writing. } \\
\text { Over-simplistic or } \\
\text { undeveloped story. } \\
\text { Tendency to be over-literal } \\
\text { or obvious. Tends to use } \\
\text { dull or clichéd ideas or } \\
\text { characters. Story lacks } \\
\text { impact or doesn't build to } \\
\text { climax or outcome. } \\
\text { Characters and point of } \\
\text { view inconsistent or } \\
\text { implausible. Lacks } \\
\text { imagery or atmosphere. }\end{array}$ & $\begin{array}{l}\text { Demonstrates a fairly clear } \\
\text { understanding of the task } \\
\text { and topic. Fairly creative } \\
\text { and engaged, with a few } \\
\text { dull or clichéd elements. } \\
\text { Story makes good overall } \\
\text { impression, keeps reader } \\
\text { engaged. Fairly strong } \\
\text { and believable characters, } \\
\text { scenes or dialogue. Has } \\
\text { some vivid images and } \\
\text { language. Understands } \\
\text { audience and } \\
\text { tone. Comfortable tempo } \\
\text { and focus }\end{array}$ & $\begin{array}{l}\text { Good, reads well and makes } \\
\text { overall sense. Good grasp of } \\
\text { task and topic. Almost free } \\
\text { of cliché and dull or } \\
\text { inappropriate language and } \\
\text { ideas. Interesting characters, } \\
\text { well-controlled point of } \\
\text { view and tempo. Keeps } \\
\text { reader gripped. Vibrant and } \\
\text { creative scenes and } \\
\text { descriptions. Maintains } \\
\text { focus and interest. Quite } \\
\text { original and exploratory. }\end{array}$ & $\begin{array}{l}\text { Excellent, virtually no } \\
\text { errors. A pleasure to read } \\
\text { and a good story overall, } \\
\text { has found right vehicle for } \\
\text { topic and audience. } \\
\text { Compelling characters and } \\
\text { scenes. Plausible and } \\
\text { well-managed settings and } \\
\text { points of view. Vivid and } \\
\text { memorable features. Good } \\
\text { focus and development. } \\
\text { Creative, literary, and } \\
\text { original. Potentially } \\
\text { publishable. }\end{array}$ \\
\hline $\begin{array}{l}\text { STRUCTURE/ } \\
\text { ORGANISATION: } \\
\text { Plot and sequence of } \\
\text { chapters, flow and } \\
\text { continuity, convincing use } \\
\text { of climax and focus; } \\
\text { selectiveness and } \\
\text { relevance to topic }\end{array}$ & $\begin{array}{l}\text { Disorganised or poorly } \\
\text { sequenced story. Plot and } \\
\text { tempo drag. Chapter } \\
\text { structure poor. Wanders } \\
\text { off topic. May have } \\
\text { repetition or irrelevance. } \\
\text { Structure not planned or } \\
\text { edited for best effect. } \\
\text { Reader loses interest. }\end{array}$ & $\begin{array}{l}\text { Sequence of chapters and } \\
\text { development of ideas } \\
\text { could improve. Plot weak. } \\
\text { Reader's interest not held. } \\
\text { Chapter breaks illogical. } \\
\text { Some irrelevance or slack } \\
\text { pace. }\end{array}$ & $\begin{array}{l}\text { Suitable sequence and } \\
\text { chapter structure for the } \\
\text { story. Strong plot, maintains } \\
\text { reader's interest most of } \\
\text { the way. Adequate climax } \\
\text { or outcome. Little } \\
\text { irrelevance or repetition. }\end{array}$ & $\begin{array}{l}\text { Good chapter structure, } \\
\text { sequence and development. } \\
\text { Interesting plot keeps } \\
\text { reader gripped. Good } \\
\text { control of tempo, climax } \\
\text { and outcome. Disciplined } \\
\text { and well-planned. }\end{array}$ & $\begin{array}{l}\text { Excellent chapter structure. } \\
\text { Superb plot keeps reader } \\
\text { wanting more. Sequence } \\
\text { and development planned } \\
\text { and polished. Disciplined, } \\
\text { focused and interesting } \\
\text { structure. Potentially } \\
\text { publishable }\end{array}$ \\
\hline $\begin{array}{l}\text { COLLABORATION/ } \\
\text { COHERENCE: } \\
\text { Teamwork, constructive } \\
\text { feedback with partner; } \\
\text { stitching together of } \\
\text { overall story; continuity } \\
\text { and consistency. }\end{array}$ & $\begin{array}{l}\text { Poor teamwork. No } \\
\text { co-ordination with partner } \\
\text { or joint input. Story } \\
\text { disjointed, lacks } \\
\text { consistency or continuity, } \\
\text { chapters are mismatched. } \\
\text { One partner too passive. }\end{array}$ & $\begin{array}{l}\text { Little teamwork or } \\
\text { co-ordination, resulting in } \\
\text { fragmentary, inconsistent } \\
\text { work. Story doesn't hang } \\
\text { together due to poor } \\
\text { continuity or stitching. }\end{array}$ & $\begin{array}{l}\text { Collaboration could improve } \\
\text { a bit, but story shows } \\
\text { co-ordination, stitching and } \\
\text { constructive feedback. } \\
\text { Partners balanced. }\end{array}$ & $\begin{array}{l}\text { Strong collaboration evident } \\
\text { in well-coordinated process } \\
\text { and coherent, consistent } \\
\text { story. Partners well-balanced } \\
\text { and equal. }\end{array}$ & $\begin{array}{l}\text { Outstanding grasp and } \\
\text { practice of collaborative } \\
\text { process. Well-coordinated, } \\
\text { consistent and coherent } \\
\text { work. Partners balanced } \\
\text { and equal. }\end{array}$ \\
\hline
\end{tabular}




\section{APPENDIX 2: Assignment brief for story and reflection}

\section{English 3/Educ 3080 \\ Reading/Writing short fiction assignment}

This assignment requires you to work with a partner from your class. You must write a story outline, a four-chapter story for the FunDza site with your partner. You must also write an individual reflection on your reading and writing processes.

\section{Section 1: Creative story (150 marks)}

Step 1: Brainstorm ideas for an outline for a four-chapter complete story.

- The story must follow the FunDza format

- The story must be geared at readers from age 13 to 22 . However, if you are foundation/intersen phase teacher, you may write a children's story (see FunDza children's link and format).

\section{Step 2: Write the outline}

- Read the FunDza story sample (yellow pack, pp. 54-55)

- Write your outline for a four-chapter story.

\section{Step 3: Write the story}

- Your collaboration may take different forms. For example, you may choose to separately write certain chapters and then share and meld them, or you may write the whole story together. Either way there needs to be a lot of negotiation, constructive feedback, processing and co-working.
- Each chapter must be $\mathbf{7 0 0 - 1 0 0 0 ~ w o r d s . ~ T h e ~ c o m p l e t e ~ s t o r y ~}$ may NOT be more than 4500-5000 words.

- You are encouraged to incorporate and adapt literary elements which you found interesting or powerful in the texts you have read.

\section{Step 4: Editing}

- Collaborative editing, correcting, overseeing, polishing and stitching together your final story -is crucial in bringing your process to its culmination in a clear, vivid and original story.

- You need to examine your story for consistency, coherence and continuity so that it hangs together as a unified narrative and is not fragmented.

\section{Section 2: Reflection (50 marks)}

This is an individually written part of the assignment.

Write a 1.5-page (1000 words approx.) text in which you reflect on your own writing processes in the course, and on your specific topic and story:

- Briefly describe your own writing journey through this course, what you have learnt about individual as well as collaborative writing and the possible implications for your teaching practices.

- How was your own writing influenced negatively or positively by the range of texts you read on the course? Provide a few specific examples.

- How did writing with the FunDza site and audience in mind, shape your writing processes? 